\title{
Peripheral Bone Mineral Density and Bone Turnover in Postmenopausal Women with Type 2 Diabetes
}

\section{Saeed $\mathrm{BO}^{1 *}$, Nixon $\mathrm{SJ}^{2}$ and Weaver $\mathrm{JU}^{3,4}$}

${ }^{1}$ Department of Clinical Biochemistry, Whittington Hospital, London, UK ${ }^{2}$ Department of Hematology, Queen Elizabeth Hospital, Gateshead, UK

${ }^{3}$ Department of Medicine, Queen Elizabeth Hospital, Gateshead, UK

${ }^{4}$ Clinical Medical Sciences, University of Newcastle-upon-Tyne, UK

\begin{abstract}
Objective: Several studies have suggested that diabetes affects Bone Mineral Density (BMD). In this study, we investigated the effect of type 2 diabetes mellitus (T2DM) on BMD and the rate of bone turnover in postmenopausal women.

Methods: This is a cross-sectional study, in which we measured peripheral bone density and markers of bone turnover in 60 postmenopausal women with T2DM and 48 age, alcohol intake and physical activity - matched control postmenopausal women without diabetes.

Results: BMD was significantly greater in subjects with T2DM than controls $\left(0.51 \mathrm{gm} / \mathrm{cm}^{2} \mathrm{vs} .0 .47 \mathrm{gm} / \mathrm{cm}^{2}\right.$ $\mathrm{p}<0.01$ ). Women with T2DM also had higher Body Mass Index (BMI) than the control group (mean: $33.7 \mathrm{~kg} / \mathrm{m}^{2} \mathrm{vs}$. $26.7 \mathrm{~kg} / \mathrm{m}^{2}, \mathrm{p}<0.0001$ ). The difference in BMD between the two groups became non-significant after adjusting for the effect of BMI by multiple regression analysis $(p=0.091)$. Osteocalcin, a marker of bone formation and three markers of bone resorption (cross-linked-N-telopeptides [NTX], C-telopeptides of type 1 collagen [CTX], and Helical peptide) were significantly reduced in T2DM compared with controls. However, the difference in the three bone resorption markers also became insignificant after adjusting for BMI.

Conclusion: This study has shown that postmenopausal women with type 2 Diabetes Mellitus apparently have higher BMD and slow bone turnover when compared with matched controls. However, the difference in BMD between the two groups became non-significant after adjusting for the effect of BMI. This study therefore does not provide evidence that T2DM per se affects bone mineral density in postmenopausal women.
\end{abstract}

Keywords: Bone density; Diabetes; Bone Turnover; Osteoporosis; Menopause

Abbreviations: T2DM: Type 2 Diabetes Mellitus; T1DM: Type 1 Diabetes Mellitus; NTX: cross-linked-N-Telopeptides; CTX: C-Telopeptides of Type 1 Collagen; DpD: Deoxypyridinoline; OC: Osteocalcin; b-ALP: Bone-specific Alkaline Phosphatase

\section{Introduction}

Menopause is associated with increased bone loss due to estrogen deficiency, which results in reduced bone strength [1]. Low BMD is a strong predictor of fracture [2]. In menopausal women, each standard deviation (SD) decrease in BMD approximately doubles the fracture risk [3].

Diabetes is a chronic disease, which has widely been reported to influence bone metabolism. However, the effect of diabetes on bone density and bone metabolism is still controversial; although most studies in type 1 Diabetes Mellitus (T1DM) have shown low BMD values [4-7]. The controversy is greater for T2DM. BMD at the vertebrae or femoral neck was not significantly different [8-10], increased [11] [12-14] or decreased [15] in T2DM compared to non-diabetic control subjects. There are fewer studies which measured BMD at the forearm, and they reported either increased $[8,16]$ no significant difference [17] or decreased [18] BMD in T2DM when compared with controls.

Many previous studies investigated bone turnover in diabetes but many early studies utilized non-specific markers like urinary calcium [19-21] and hydroxyproline [21,22]. Although there are now more specific markers for bone turnover, they tend to exhibit large intraindividual variability, this is specialy the case for urinary markers which need to be adjusted to urinary creatinine $[23,24]$. The few reports on the status of bone turnover in T2DM mostly reported low bone turnover $[14,25]$ with some exceptions [22]. The previous studies in people with diabetes included predominantly either women or both women and men. The attention to type of diabetes mellitus was not uniform. With some exceptions [26], BMI was either not measured or not included in the analysis in most studies.

To compensate for the effect of the wide variability of bone marker levels, we measured a combination of some of the most specific bone turnover markers available. The bone formation markers studied were: osteocalcin (OC) and bone specific alkaline phosphatase (b-ALP). The bone resorption markers were: cross-linked-N-telopeptides (NTX) measured as osteomark, C-telopeptides of type 1 collagen (CTX) measured as $\beta$-crosslaps, deoxypyridinoline (DpD) and helical peptide. Helical peptide is a relatively new bone marker based on measurement of residues 620 - 633 derived from the helical peptide of the $\alpha 1$ chain of type 1 collagen [27]. It has never been measured in subjects with diabetes before. The other bone resorption markers (NTX, CTX and

*Corresponding author: Dr. Bakri O Saeed, Department of Clinical Biochemistry, Whittington Hospital, 5 Rufford Street, London, UK, Tel: +442076092294; E-mail: saeedbakri@hotmail.com

Received June 18, 2012; Accepted July 02, 2012; Published July 06, 2012

Citation: Saeed BO, Nixon SJ, Weaver JU (2012) Peripheral Bone Mineral Density and Bone Turnover in Postmenopausal Women with Type 2 Diabetes. J Diabetes Metab S1:007. doi:10.4172/2155-6156.S1-007

Copyright: (c) 2012 Saeed BO, et al. This is an open-access article distributed under the terms of the Creative Commons Attribution License, which permits unrestricted use, distribution, and reproduction in any medium, provided the original author and source are credited. 
DpD) have been barely studied before in postmenopausal patients with T2DM $[10,14]$. It has been known for some time that obesity protects against osteoporosis [11,28-30]. Thus we hypothesised that in women with T2DM, bone turnover is reduced resulting in increased BMD. Those findings are likely to be related to higher BMI commonly seen in T2DM.

\section{Patients and Methods}

Consecutive female patients were recruited from Annual Review and Follow up Diabetic Clinics. T2DM was diagnosed according to the criteria of the National Diabetes data Group [31]. Controls were recruited either as relatives of patients with diabetes or members of Gateshead Health Trust who responded to invitation by poster or Hospital Newsletter. They did not have any illness or were on any medication which might affect bone turnover. Controls have normal fasting glucose and $\mathrm{HbAlc}$ levels. The BMD measurements were done by the same personnel. Postmenopausal status of participants was confirmed by interview and measurement of follicle stimulating hormone levels. The study was approved by the local ethics committee and all study subjects have given their written consent.

The characteristics of patients and controls are detailed in table 1. Nine diabetic patients were treated with diet alone, 9 patients with insulin alone, 16 patients were treated with a combination of insulin and oral hypoglycemic agents and 27 patients were treated with oral hypoglycemic agents.

Waist hip measurement was recorded at midpoint between lower rib margin and anterior iliac crest and hip at its widest aspect by single observer on one occasion. Physical activity was estimated by patients themselves. Menopausal status was confirmed by interview and FSH levels. Blood pressure was measured in fasting state after 5 minutes sitting using OMRON automatic digital blood pressure monitor HEM$705 \mathrm{CP}$. We used patient's right arm with appropriate cuff size. During the measurement, patients were not speaking and remained in relaxed position with uncrossed legs.

Peripheral BMD was measured in the distal non-dominant radius using a peripheral osteometer DTX 2000, (Osteometer MediTech, Inc, Hawthorner, CA, USA). Absolute values were recorded, together with $\mathrm{T}$ and $\mathrm{Z}$ scores.

Bone formation markers (osteocalcin and bone specific alkaline phosphatase) were measured in a fasting serum sample by EIA (MetraBiosystems Inc., Mountainview, CA). Serum $\beta$-cross laps were measured on a Roche Elecsys 2010 Analyzer, Lewes, UK. NTX were measured as urinary osteomark (Ostex, Seattle, WA, USA), helical peptide was measured by EIA (Quidel Corporation, Mountain view, CA, USA) and urinary DpD measured on a second, fasting, early morning urine sample, using the Pyrilinks-D assay (MetraBiosystems Inc., Mountainview, CA). Results for urinary markers were expressed as per creatinine. Samples were stored at $-30^{\circ} \mathrm{C}$ until analysed.

HbA1c was measured on the Menarini HPLC system. Plasma glucose and serum creatinine were measured on a Roche Modular Analyser (Roche Diagnostics, Mannheim, Germany).

\section{Statistical analysis}

Analyses were performed with the statistical package SPSS/PC + (SPSS Inc, Chicago, iII). All tests used were two-tailed and $\mathrm{p}<0.05$ was considered significant. The normality of distribution of any variable was assessed using the Kolmogorov-Smirnov test and skewed distributions were logarithmically transformed. Comparisons between groups (T2DM patients and controls) were performed using the unpaired t-test or the unpaired Wicoxon rank test for nonparametric values. Correlation analysis was performed using Pearson's correlation coefficient.

Multiple regression analysis was used to adjust the effect of weight on BMD and bone markers. In the multiple regression analysis, BMD was used as a dependent variable and BMI or coded group allocation (either diabetic or non-diabetic) as independent variables. To adjust for the effect of BMI on the levels of metabolic bone markers, each bone marker was considered as a dependent variable and BMI or coded group allocation as independent variables. The difference between the two groups was considered non-significant when the $\mathrm{p}$ value for the group allocation was $>0.05$.

\section{Results}

The main characteristics of the study groups were detailed in table 1. The groups were matched for age, activity levels, and alcohol intake. Patients with T2DM had significantly greater tobacco consumption than the non-diabetic group (Table 1). BMI was greater in patients with T2DM than in the controls (mean 33.7 vs. 26.7, $\mathrm{p}<0.0001$ ).

BMD was significantly greater in women with $\mathrm{T} 2 \mathrm{DM}$ than in controls (mean: $0.51 \mathrm{gm} / \mathrm{cm}^{2}$ vs. $0.47, \mathrm{p}<0.01$ ). BMD did not correlate with $\mathrm{HbA} 1 \mathrm{c}$ or duration of diabetes. There was no significant correlation between BMD and BMI. Three bone resorption markers ( $\beta$-crosslaps, helical peptide and osteomark) were significantly lower in the diabetic group than the control group. Osteocalcin, a marker of bone formation was also lower in the diabetic group (Table 2). Bone-specific alkaline phosphatase and $\mathrm{DpD}$ levels were similar in both groups.

The effect of BMI on BMD was investigated by multiple regression analysis. The results showed that after adjusting for BMI, the difference in BMD levels between the diabetic and the non-diabetic group became non-significant. Adjustment for BMI also abolished the significant difference in the levels of the bone resorption markers. The difference between the two groups in osteocalcin levels remained significant even after adjusting for BMI (Table 3 and 4).

\section{Discussion}

Postmenopausal bone loss is associated with increased bone

\begin{tabular}{|l|l|l|l|}
\hline & Controls & Patients & $p$ \\
\hline Age (years) & 58.4 & 60.3 & $\mathrm{~ns}$ \\
\hline BMI (kg/m²) & $26.8+4.4$ & $33+76$ & $\mathrm{P}<0.0001$ \\
\hline Waist/hip ratio & $0.78(067-094)$ & $0.88(0.74-1.57)$ & $\mathrm{P}<0.0001$ \\
\hline $\begin{array}{l}\text { Systolic blood pressure } \\
\text { (mmHg) }\end{array}$ & $136.4+19.2$ & $148.4+21.2$ & $\mathrm{P}<0.01$ \\
\hline $\begin{array}{l}\text { Diastolic blood pressure }(\mathrm{mm} \\
\text { Hg) }\end{array}$ & $84.7+11.2$ & $86.7+11.8$ & $\mathrm{~ns}$ \\
\hline HRT use\% & 50 & 35 & $\mathrm{~ns}$ \\
\hline Age at menarche (years) & $12.6+1.6$ & $12.8+1.9$ & $\mathrm{~ns}$ \\
\hline Age at menopause (years) & $46.9+6$ & $47.7+5.9$ & $\mathrm{~ns}$ \\
\hline Duration of menopause (years) & $11.5+6.7$ & $11.7+5.5$ & $\mathrm{~ns}$ \\
\hline $\begin{array}{l}\text { Physical activity (miles walked } \\
\text { per week) }\end{array}$ & $3(0-35)^{\star}$ & $1(0-35)^{\star}$ & $\mathrm{ns}$ \\
\hline Smoking (mean pack years) & $0(0-35)^{\star}$ & $8(0-170)^{\star}$ & $\mathrm{P}<0.05$ \\
\hline
\end{tabular}

* Values reported as median and range due to skewed distribution of analyte. Statistical significance was assessed by unpaired Wilcoxon test

Table 1: Characteristics of the study populations. 


\begin{tabular}{|l|l|l|l|}
\hline & Controls & Patients & $P$ value \\
\hline BMD $\left(\mathrm{g} / \mathrm{cm}^{2}\right)$ & $0.47+0.09$ & $0.51+0.09$ & $\mathrm{P}<0.05$ \\
\hline BMD $(\mathrm{z}-\mathrm{score})$ & $0.773+1.43$ & $1.55+1.44$ & $\mathrm{P}<0.01$ \\
\hline Serum b-ALP $(\mathrm{U} / \mathrm{L})$ & $16.56+5.19$ & $17.97+6.72$ & $\mathrm{~ns}$ \\
\hline Serum Osteocalcin $(\mathrm{ng} / \mathrm{mL})$ & $9+3.8$ & $5.6+2.4$ & $\mathrm{P}<0.0001$ \\
\hline Urinary DpD $(\mathrm{nm} / \mathrm{mmol} \mathrm{Cr})$ & $7.7+3.1$ & $8.1+5.2$ & $\mathrm{~ns}$ \\
\hline Serum b-Cross laps $(\mathrm{nmol} / \mathrm{L})$ & $0.41+0.31$ & $0.26+0.17$ & $\mathrm{P}<0.01$ \\
\hline $\begin{array}{l}\text { Urinary Osteomark }(\mathrm{nmol} \\
\text { BCE/mM Cr) }\end{array}$ & $42(11.2-370)^{*}$ & $34.7(3.6-166)^{*}$ & $\mathrm{P}<0.05$ \\
\hline $\begin{array}{l}\text { Urinary Helical peptide }(\mathrm{mg} / \\
\text { mmol Cr) }\end{array}$ & $48(12.7-478.9)^{*}$ & $33.1(1.9-145.6)^{*}$ & $\mathrm{P}<0.01$ \\
\hline
\end{tabular}

*Values reported as median and range due to skewed distribution of analyte. Statistical significance was assessed by unpaired Wilcoxon test

Table 2: Comparison of the Bone mineral density (BMD) and concentrations of bone turnover markers in the two study groups.

\begin{tabular}{|l|l|l|}
\hline Independent variable & Coefficient & $\boldsymbol{p}$ value \\
\hline Body Mass Index & -0.6987 & \\
\hline Group & -3.799 & $<0.00010$ \\
\hline
\end{tabular}

Bone mineral density $\left(\mathrm{gm} / \mathrm{cm}^{2}\right)$ was dependent variable. The Independent variables were Body mass index and group allocation. The results show that the difference in bone mineral density between the diabetic and the control group was no longer significant after adjustment for body mass index $(p=0.0901)$

Table 3: Use of multiple regression analysis to adjust for the effects of Body mass index on bone mineral density.

\begin{tabular}{|l|l|l|}
\hline Dependent variable & $\begin{array}{l}\text { Coefficient for Group allocation } \\
\text { (diabetic or nond0abetic control) }\end{array}$ & $\boldsymbol{p}$ value \\
\hline Osteocalcin & 1.7799 & $0.0175^{\star}$ \\
\hline b-Cross Laps & -0.0898 & 0.4618 \\
\hline Helical peptide & 16.5653 & 0.1666 \\
\hline Osteomark & 10.1525 & 0.4054 \\
\hline
\end{tabular}

In each occasion, a metabolic bone marker was dependent variable. The Independent variables were Body mass index and group allocation. The results show that the difference in metabolic bone markers between the diabetic and the control group was no longer significant after adjustment for body mass index, except for osteocalcin* $(p=0.0175)$

Table 4: Use of multiple regression analysis to adjust for the effects of Body mass index on concentrations of metabolic bone markers.

turnover, which has been confirmed by demonstrating raised levels of markers of bone formation and resorption [27,32,33] and studies on iliac crest biopsies [34].

In this study we found a significantly higher BMD at the forearm in postmenopausal women with T2DM when compared with controls. Rates of smoking were significantly higher among patients with diabetes. Smoking is associated with decreased BMD and increased bone turnover [2,35-37]. It is therefore possible that the true BMD in the diabetic group is slightly higher than that reported in this study.

There was however, significant difference in the BMI measurements between the two groups. It has been known for some time that obesity protects against osteoporosis [11,28-30]. We therefore adjusted for the effect of BMI on BMD difference between the diabetic patients and controls, by multiple regression analysis. The results showed that after adjusting for BMI, the difference in BMD levels between the diabetic and the non-diabetic group became non-significant (Table 3). This result is in keeping with previous studies, which demonstrated a protective effect of body weight on the bone mass of axial skeleton $[11,38,39]$ and proximal femur [40]. More recently it has been shown that women with diabetes had significantly higher BMD, which was significantly correlated to BMI at forearm and spine but not at hip site [41]. It has been suggested that varying BMD measurements have been noted at different anatomic regions however no reference was made to BMI of the studied subjects [42]. The possible protective effect of T2DM on bone mass was presumed to be due to a mechanical effect, increased circulating estrogen caused by conversion of androgens to estrogen or hyperinsulinemia [43-45]. The association between obesity and increased BMD was also thought to be caused by high leptin concentrations in obese people [46]. Leptin plays a direct role in stimulating osteoblast number and activity in cell culture [47]. However, in a recent study on postmenopausal women with T2DM, There was no correlation between low BMD and leptin, adiponectin and insulin resistance [48]. In our study we have not shown any increase in the bone formation markers in diabetes but on the contrary a significant reduction was seen in osteocalcin levels.

The difference in osteocalcin levels between the two groups remained statistically significant after adjusting for BMI, although less significant than before adjustment for BMI. It is possible that bone formation, as reflected by osteocalcin levels, is reduced in the diabetic group, irrespective of BMI. There is also evidence that hyperglycemia inhibits osteocalcin release from osteoblasts and can therefore contribute to the reduced levels in diabetic patients [49].

The two bone formation markers studied behaved differently; while OC levels were significantly reduced in postmenopausal women with T2DM, b-ALP levels were comparable between the two groups. The discrepancy of bone formation makers has been reported from several studies. One possible explanation for such discrepancy could be that different bone formation markers reflect different stages of osteoblastic differentiation. While alkaline phosphatase activity is produced by mature cells, OC is produced during the mineralization phase [50,51]. Previous studies in T2DM showed a more consistent decrease in OC levels in diabetic patients compared to non-diabetic controls [52-56].

Most of the resorption markers levels measured were significantly lower in women with diabetes, suggesting a slow bone turnover in this group. Most previous studies reported decreased bone resorption in T2DM based on low DpD and $\beta$-cross laps levels $[10,14]$, while other studies which measured urinary $\mathrm{DpD}$ levels only, found no difference between diabetic patients and controls $[55,56]$.

The difference in the bone resorption markers between diabetic and nondiabetic control group became insignificant after adjusting for BMI by multiple regression analysis. This suggests that the effect of BMI on preservation of bone in the diabetic group was caused by slowing down bone turnover as was also shown by others $[14,57]$.

This is the largest to date prospective study of postmenopausal women with type 2 diabetes that measured BMD and a combination of several highly specific bone markers.

This is the first report on helical peptide in relation to BMD measurements, which proved the usefulness of helical peptide in the assessment of bone turnover. Whether the increased BMD in diabetic patients will protect them from fractures still requires further investigation. Although BMD is a strong predictor of fracture susceptibility in postmenopausal women, it is not the only one. Factors like bone size and skeletal architecture are also important predictors of fracture $[2,58,59]$. The overall susceptibility to fracture in this population will likely depend on the interplay of several factors, which may vary in different populations. This may explain the controversy 
surrounding the previous studies on the association between diabetes and fractures, which produced conflicting results $[4,7,12,60]$.

Although increased BMD in T2DM is seen as an advantage this does not necessarily translate in this group into a reduced incidence of fractures as has been suggested before [61]. Recently, a large study demonstrated that despite having higher bone density, diabetic women have lower indices of femoral neck strength relative to load, consistent with higher fracture risk [62]. Another multi-centre study showed that obesity is not protective against fracture in postmenopausal women and is associated with increased risk of ankle and upper leg fractures [63]. The association between obesity and fracture in postmenopausal women was also found to be site-dependent, obesity being protective against hip and pelvis fractures but associated with an almost 30\% increase in risk for proximal humerus fractures when compared with normal/underweight women [64].

This indicates that other factors, including co-morbidities associated with diabetes such as neuropathy or postural hypotension may increase the risk of fracture regardless of higher BMD. Diabetic polyneuropathy is associated with high bone turnover in postmenopausal women [65]. Insulin resistance appears to play an important role in bone strength reduction in diabetes [62].

In conclusion, we have shown that in patients with type $2 \mathrm{DM}$ bone turnover is reduced resulting in increased BMD. Those findings are related to higher BMI in comparison to healthy controls. Further work is required to clarify the relationship between BMD in postmenopausal women with T2DM and susceptibility to fracture.

\section{References}

1. Frost HM (1999) On the estrogen-bone relationship and postmenopausal bone loss: a new model. J Bone Miner Res 14: 1473-1477.

2. Cummings SR, Nevitt MC, Browner WS, Stone K, Fox KM, et al. (1995) Risk factors for hip fractures in white women. Study of osteoporotic fractures research group. $\mathrm{N}$ Engl J Med 332: 767-773.

3. Marshall D, Johnell O, Wedel H (1996) Meta-analysis of how well measures of bone mineral density predict occurrence of osteoporotic fractures. BMJ 312 1254-1259.

4. Heath DH, Melton LJ, Chu CP (1980) Diabetes mellitus and risk of skeletal fracture. N Engl J Med 303: 567-570.

5. Hui SL, Epstein S, Johnston CC (1985) A prospective study of bone mass in patients with type 1 diabetes. J Clin Endocrinol Metab 60: 74-80.

6. Mathiassen B, Nielsen S, Johansen JS, Hartwell D, Ditzel J, et al. (1990) Long term bone loss in insulin-dependent diabetes patients with microvascular complications. J Diabet Complications 4: 145-149

7. Melchior TM, Sorensen H, Torp-Pedersen C (1994) Hip and distal arm fracture rates in peri-and postmenopausal insulin-treated diabetic females. J Intern Med 236: 203-208.

8. Barret-Connor E, Holbrook TL (1992) Sex differences in osteoporosis in older adults with non-insulin dependent diabetes mellitus. JAMA 268: 3333-3337.

9. Wakasugi M, Wakao R, Tawata M, Gan N, Koizumi K, et al. (1993) Bone mineral density by dual energy $\mathrm{X}$-ray absorptiometry in patients with non-insulin dependent diabetes mellitus. Bone 14: 29-33.

10. Isaia GC, Ardissone P, Di Stefano M, Ferrari D, Martina V, et al. (1999) Bone metabolism in type 2 diabetes mellitus. Acta Diabetol 36: 35-38.

11. Bauer DC, Browner WS, Cauley JA, Orwoll ES, Scott JC, et al. (1993) Factors associated with appendicular bone mass in older women. The study of osteoporotic fractures Research Group. Ann Intern Med 118: 657-665.

12. van Daele PL, Stolk RP, Burger H, Algra D, Grobee DE, et al. (1995) Bone density in non-insulin dependent diabetes mellitus. The Rotterdam Study. Ann Intern Med 122: 409-414.
13. Kwon DJ, Kim JH, Chung KW, Lee JW, Kim SP, et al. (1996) Bone mineral density of the spine using dual energy $\mathrm{x}$-ray absorptiometry in patients with noninsulin dependent diabetes mellitus. J Obstet Gynaecol Res 22: 157-162

14. Christensen JO, Svendesen OL (1999) Bone mineral in pre-and postmenopausa women with insulin-dependent and non-insulin-dependent diabetes mellitus. Osteoporos Int 10: 307-311.

15. Okuno Y, Nishizawa Y, Sekiya K, Hagiwara S, Miki T, et al. (1991) Total and regional bone mineral content in patients with non-insulin-dependent diabetes mellitus. J Nutr Sci Vitaminol 37: S43-S49.

16. Johnston CC, Hui S, Longcope C (1985) Bone mass and sex steroid concentrations in postmenopausal Caucasian diabetics. Metabolism 34: 544550 .

17. Giacca A, Fassina A, Gaviezel F, Cattaneo AG, Caldirola G, et al. (1988) Bone mineral density in diabetes mellitus. Bone 9: 29-36.

18. Levin ME, Boisseau VC, Avioli LV (1976) Effects of diabetes mellitus on bone mass in juvenile and adult-onset diabetes. New Engl J Med 294: 241-245.

19. Raskin P, Stevenson MR, Barilla DE, Pak CY (1978) The hypercalciuria of diabetes mellitus: its amelioration with insulin. Clin Endocrinol 9: 329-335.

20. McNair P, Christensen MS, Madsbad S, Christensen C, Transbol I (1981) Hypoparathyroidism in diabetes mellitus. Acta Endocrinol 96: 81-86

21. Gallacher SJ, Fenner JA, Fisher BM, Quin JD, Fraser WD, et al. (1993) An evaluation of bone density and turnover in premenopausal women with type 1 diabetes mellitus. Diabet Med 10: 129-133.

22. Selby PL, Shearing SM, Marshall SM (1995) Hydroxyproline excretion is increased in diabetes mellitus and related to the presence of microalbuminuria. Diabet Med 12: 240-243

23. Greenspan SL, Dresner-Pollak R, Parker RA, London D, Ferguson L (1997) Diurnal variation in bone mineral turnover in elderly men and women. Calcif Tissue Int 60: 419-423

24. Souberbielle JC, Cormier C, Kindermans C (1999) Bone markers in clinical practice. Curr Opin Rheumatol 11: 312-319.

25. Rico H, Hernandez ER, Cabranes JA, Gomez-Castresana F (1989) Suggestion of a deficit in osteoblastic function in diabetes mellitus: the possible cause of osteopenia in diabetics. Calcif Tissue Int 45: 71-73.

26. Rico H, Hernandez ER, Cabranes JA, Gomez-Castresana F (1989) Suggestion of a deficit in osteoblastic function in diabetes mellitus: the possible cause of osteopenia in diabetics. Calcif Tissue Int 45: 71-73.

27. Garnero P, Dalmas PD (2003) An immunoassay for type I collagen alpha helicoidal peptide 620-633, a new marker of bone resorption in osteoporosis. Bone 32: 20-26.

28. Harris S, Dallal GE, Dawson-Hughes B (1992) Influence of body weight on rates of change in bone density of the spine, hip and radius in postmenopausa women. Calcif Tissue Int 50: 19-23

29. Felson DT, Zhang Y, Hannan MT, Anderson JJ (1993) Effects of weight and bone mass index on bone mineral density in men and women: The Framingham study. J Bone Miner Res 8: 567-573

30. Albala C, Yanez M, Devoto E, Sostin C, Zeballos L, et al. (1996) Obesity as a protective factor for postmenopausal osteoporosis. Int J Obes Relat Metab Disord 20: 1027-1032

31. The expert committee on the diagnosis and classification of diabetes mellitus (1997) Diabetes Care 20: 1183-1197.

32. Kanis JA (1994) Pathogenesis of osteoporosis and fracture. In: Osteoporosis: 28-34

33. Ravn P, Rix M, Andreassen H, Clemmesen B, Bidstrup M, et al. (1997) High bone turnover is associated with low bone mass and spinal fracture in postmenopausal women. Calcif Tissue Int 60: 255-260.

34. Eastell R, Colwell A, Hampton L, Reeve J (1997) Biochemical markers of bone resorption compared with estimates of bone resorption from radiotracer kinetic studies in osteoporosis. J Bone Miner Res 12: 59-65.

35. Johnell O, Gulberg B, kanis JA, Allander E, Elffors L, et al. (1995) Risk factors for hip fractures in European women. The MEDOS Study. Mediterranean Osteoporosis Study. J Bone Miner Res 10: 1802-1815.

36. de Valk-de Roo GW, Netelenbos JC, Peters-Muller IR, Voetberg GA, van de 
Citation: Saeed BO, Nixon SJ, Weaver JU (2012) Peripheral Bone Mineral Density and Bone Turnover in Postmenopausal Women with Type 2 Diabetes. J Diabetes Metab S1:007. doi:10.4172/2155-6156.S1-007

Weijer PH, et al. (1997) Continuously combined hormone replacement therapy and bone turnover: the influence of dydrogesterone dose, smoking and initial degree of bone turnover. Maturitas 28:153-162.

37. Oncken C, Prestwood K, Cooney JL, Unson C, Fall P, et al. (2002) Effects of smoking cessation or reduction on hormone profiles and bone turnover in postmenopausal women. Nicotine Tob Res 4: 451-458.

38. Ribot C, Tremollieres F, Pouilles JM, Bonneau M, Germain F, et al. (1988) Obesity and postmenopausal bone loss: The influence of obesity and vertebral density and bone turnover in postmenopausal women. Bone 8: 337-331.

39. Nordin BE, Need AG, Bridges A, Horowitz M (1992) Relative contribution of years since birth, age, and weight to vertebral density in postmenopausal women. J Clin Endocrinol Metab 74: 20-23.

40. Rishaug U, Birkeland KI, Falch JA, Vaaler S (1995) Bone mass in non-insulindependent diabetes mellitus. Scand J Clin Lab Invest 55: 257-562.

41. Kao WH, Kammerer CM, Schneider JL, Bauer RL, Mitchell BD (2003) Type 2 diabetes is associated with increased bone mineral density in Mexican American women. Arch Med Res 34: 399-406

42. Sert M, Tetiker T, Kirim S, Soyupak S, Canataroglu A, et al. (2003) Type 2 diabetes mellitus and osteopenia : is there an association? Acta Diabetol 40: 105-108

43. Barrett-Connor E, Kritz-Silverstein D (1996) Does hyperinsulinaemia preserve bone? Diabetes Care 19: 1388-1392.

44. Stolk RP, Van-Daele PL, Pols HA, Burger H, Hoffman A, et al. (1996) Hyperinsulinaemia and bone mineral density in an elderly population: The Rotterdam Study. Bone 18: 545-549.

45. Piepkorn B, Kann P, Forst T, Andreas J, Pfützner A, et al. (1997) Bone mineral density and bone metabolism in diabetes mellitus. Horm Metab Res 29: 584591.

46. Scariano JK, Garry PJ, Montoya GD, Chandani AK, Wilson JM, et al. (2003) Serum leptin levels, bone mineral density and osteoblast alkaline phosphatase activity in elderly men and women. Mech Ageing Dev 124: 281-286.

47. Reseland JE, Syversen U, Bakke I, Qvigstad G, Eide LG, et al. (2001) Leptin is expressed in and secreted from primary cultures of human osteoblasts and promotes bone mineralization. J Bone Miner Res 16: 1426-1433.

48. Koroglu BK, Kiris F, Ersoy IH, Sutcu R, Yildiz M, et al. (2011) Relation of leptin adiponectin and insulin resistance to bone mineral density in type 2 diabetic postmenopausal women. Endokrynol Pol 62: 429-435.

49. Okazaki R, Totsuka Y, Hamano K, Ajima M, Miura M, et al. (1997) Metabolic improvement of poorly controlled noninsulin-dependent diabetes mellitus decreases bone turnover. J Clin Endocrinol Metab 82: 2915-2920.

50. Ristelli L, Ristelli J (1993) Biochemical markers of bone metabolism. Annals of Medicine 25: 385-393.

51. Swaminathan R (2001) Biochemical markers of bone turnover. Clin Chim Acta 313: 95-105.
52. Pietschmann P, Schernthaner G, Woloszczuk W (1988) Serum osteocalcin levels in diabetes mellitus: analysis of the type of diabetes and microvascular complications. Diabetologia 31: 892-895.

53. Pedrazzoni M, Ciotti G, Pioli G, Girasole G, Davoli L, et al. (1989) Osteocalcin levels in diabetic subjects. Calcif Tissue Int 45: 331-336.

54. Gregorio F, Cristallani S, Santeusanio F, Filipponi P, Fumelli P (1994) Osteopenia associated with non-insulin-dependent diabetes mellitus: What are the causes? Diabetes Res Clin Pract 23: 43-54.

55. Cakatay U, Telci A, Kayali R, Akcay T, Sinas A, et al. (1998) Changes in bone turnover on deoxypyridinoline levels in diabetic patients. Diabetes Res Clin Pract 40: 75-79.

56. Rosato MT, Schneider SH, Shapses SA (1998) Bone turnover and insulin-like growth factor I levels increase after improved glycemic control in noninsulindependent diabetes mellitus. Calcif Tissue Int 63: 107-111.

57. Akin O, Gol K, Akturk M, Erkaya S (2003) Evaluation of bone turnover in postmenopausal patients with type 2 diabetes mellitus using biochemical markers and bone mineral density measurements. Gynecol Endocrinol 17: 19 29.

58. Seeman E, Duan Y, Fong C, Edmonds J (2001) Fracture site-specific deficit in bone size and volumetric density in men with spine or hip fractures. $J$ Bone Miner Res 16: 120-127.

59. Henrik G, Ahlborg MD, Olof J, Charles HT, Gunnar R, et al. (2003) Bone loss and bone size after menopause. N Engl J Med 349: 327-334.

60. Forsen L, Meyer HE, Midthjell K, Edna TH (1999) Diabetes mellitus and the incidence of hip fracture: results from the Nord-Trondelag Health Survey Diabetologia 42: 920-925.

61. Schwartz AV, Sellmeyer DE, Ensrud KE, Cauley JA, Tabor HK, et al. (2001) Older women with diabetes have an increased risk of fracture: a prospective study. J Clin Endocrinol Metab 86: 32-38.

62. Ishii S, Cauley JA, Crandall CJ, Srikanthan P, Greendale GA, et al. (2012) Diabetes and femoral neck strength: findings from the Hip Strength Across the Menopausal Transition Study. J Clin Endocrinol Metab 97: 190-197.

63. Compston JE, Watts NB, Chapurlat R, Cooper C, Boonen S, et al. (2011) Obesity is not protective against fracture in postmenopausal women: GLOW. Am J Med 124: 1043-1050

64. Prieto-Alhambra D, Premaor MO, Fina Avilés F, Hermosilla E, Martinez-Laguna D, et al. (2012) The association between fracture and obesity is site-dependent: a population-based study in postmenopausal women. J Bone Miner Res 27: 294-300.

65. Rasul S, Ilhan A, Wagner L, Luger A, Kautzky-Willer A (2012) Diabetic polyneuropathy relates to bone metabolism and markers of bone turnover in elderly patients with type 2 diabetes: greater effects in male patients. Gend Med 9: 187-196.
This article was originally published in a special issue, Diabetic Osteoporosis handled by Editor(s). Dr. Laura McCabe, Michigan State University, USA 